\title{
Nonlinear Static Analysis of UHV Tower with Considering Joint Slippage
}

\author{
Wenqiang Jiang ${ }^{\mathrm{a}}$,Ziyang Zhang ${ }^{\mathrm{b}}$ and Zhangqi Wang ${ }^{\mathrm{c}}$ \\ Department of Mechanical Engineering, North China Electric Power University, Baoding, China \\ ajwq1980@hotmail.com, 'buadianzzy@126.com, wangzq2093@163.com
}

Keywords: UHV Tower; Joint slippage; Nonlinear Static analysis

\begin{abstract}
In the traditional lattice tower design process, the effects of bolted joint slippage are not taken into account, which cause great discrepancy between numerical analysis and full tower tests. In this paper, several joint slippage models are presented with considering the joint connection types and number of bolts. The finite element models of UHV transmission tower are built with introduce the joint slippage effects, and then the inner force and deformation of transmission tower under strong wind load case was studied and the influence of joint slippage are discussed by using the nonlinear static analysis method.
\end{abstract}

\section{Introduction}

In recent years, the rapid developments of ultra-high voltage (UHV) transmission lines construction become an inevitable trend in China. In order to meet the requirements of electrical safety distances, the spatial dimension of lattice transmission tower became significantly larger compared with traditional tower. Traditionally, ordinary bolt should not be used as bearing type connection in the steel structure. However, in practice the ordinary bolts are always used in shearing connection in transmission tower. Due to the small bolt pre-tightening force and structural clearance between the bolt and the bolt hole, the connected components may occurs slippage in this connection type when the tower under external loading[1-2]. Therefore, the bolted joint is no longer completely rigid in axial direction, which should be assumed as semi-rigid connection. As shown in Fig. 1 is the bolted joint slippage diagram.

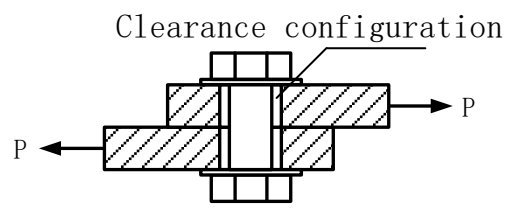

(a) Before Slippage

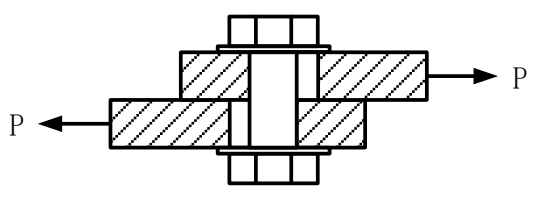

(b) After Slippage

Fig.1. Bolted joint deformation

For statically determinate structure, bolt joint slippage does not significantly effects the internal force of structure, but for the statically indeterminate UHV transmission tower, bolted joint slippage will affect both the internal force and the deformation [3-5]. Accordingly, in order to accurately predict the internal force and deformation in the whole load-displacement process of transmission tower, it is necessary to apply the corresponding bolt slippage model to different types of bolted joints [6-7].

In this paper, several joint slippage models are present according to the connection type and number of bolts, which are applied to the UHV transmission tower. The joint slippage effects on the member forces and deformation of tower structure are studied using the nonlinear static analysis.

\section{2. bolted Joint slippage in tower}

There are several types of bolted joint in the transmission tower depend on the bolt number and configuration [1]. Commonly, they are divided into two types: single-leg and lap-splice bolted joint. 
As shown in figure 1 (a) is the lap-splice bolted joint, and figure 1 (b) and (c) shows the single-leg bolted joint.

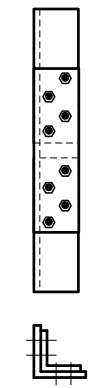

(a)

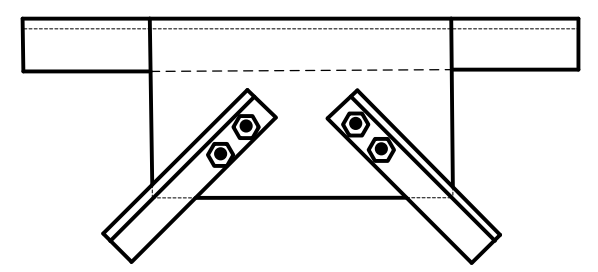

(b)

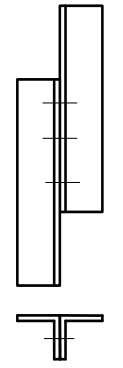

(c)

Fig.2 Bolted joint in transmission tower

In this paper, the joint slippage model in literature [2] are adopted. The parameters of the joint slippage model are determined according the difference of bolt number, and the corresponding bolt slip models are shown in Fig. 3 for single-leg and lap-splice bolted joint respectively.

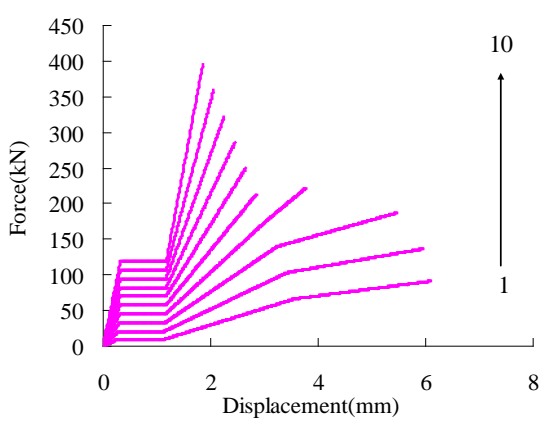

(a) Single-leg joint

Fig.3 Joint slippage models

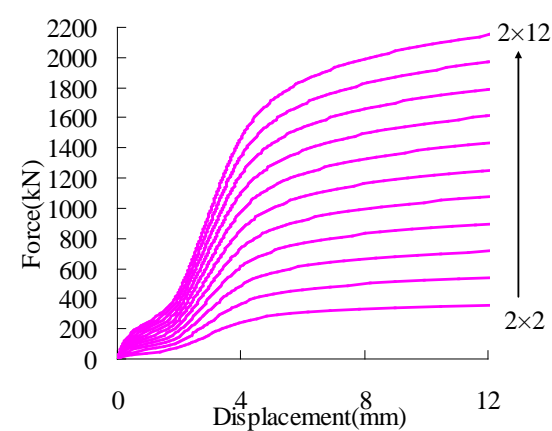

(b) lap-splice joint

\section{Analysis of the tower}

In this paper, the ZMP2 type UHV transmission line tower was chosen for study, which has a height of $78.4 \mathrm{~m}$. During analysis, the commercial software NIDA was used, and two finite element models are created which consist of rigid joint tower model (Model I) and the tower model with considering joint slippage (Model II). Further more, the strong wind load condition are selected to study the joint slippage effects on the member inner force and deformation of tower.
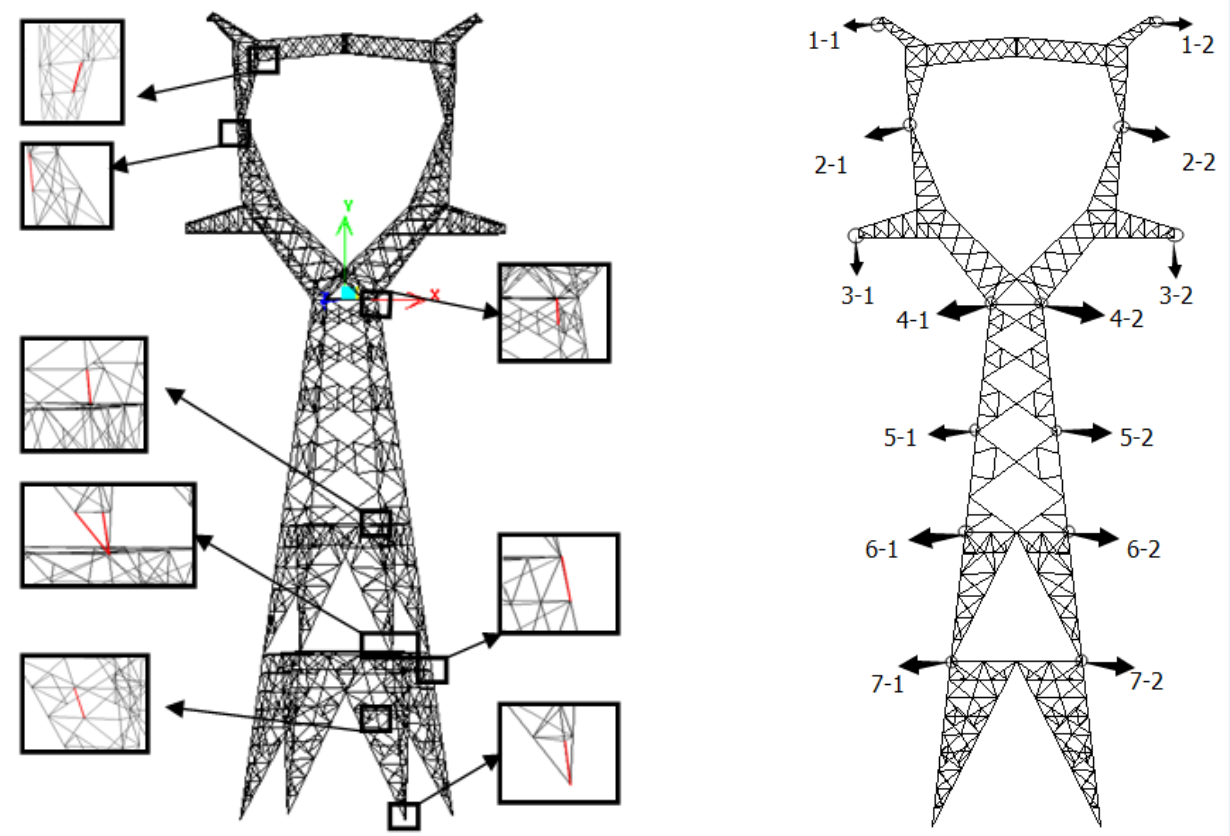
(a) The measuring members

(b) The measuring nodes

Fig.4 Measuring point locations

\subsection{Member axial force}

Fig. 5 shows the axial force of the tower member at different design load level. The location of the members can be found in the Fig.4 (a).As can be seen in the Figure, the axial forces of members are almost same at different design load level. The error is increased as the increasing of load level, and the maximum errors at $100 \%$ design load is around $10 \%$, which means the joint slippage will slightly affect the inner force of the select member.

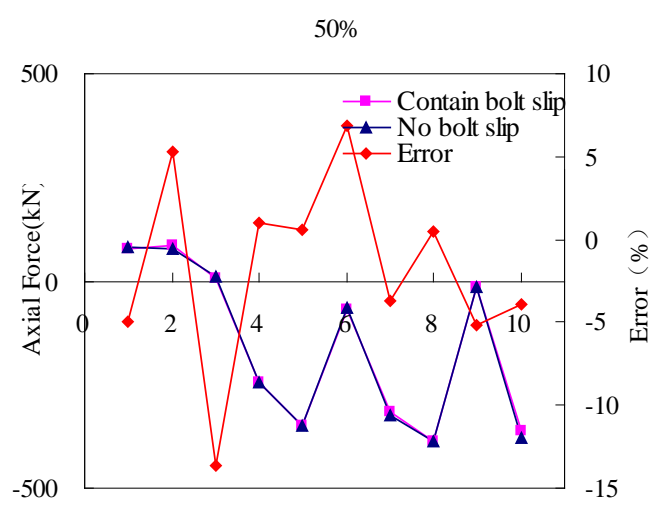

(a) $50 \%$ design load

$90 \%$

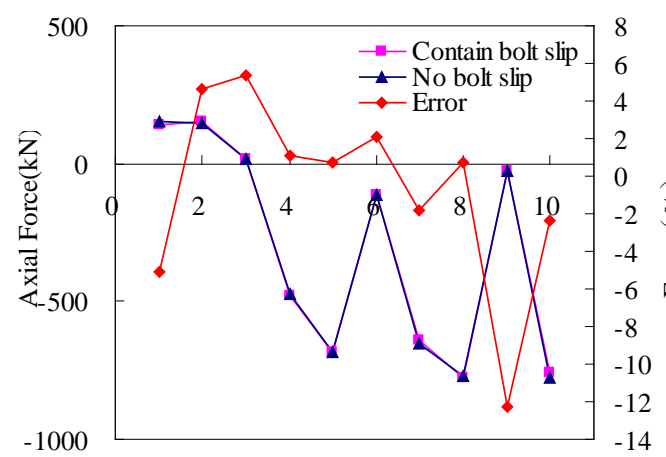

(c) $90 \%$ design load

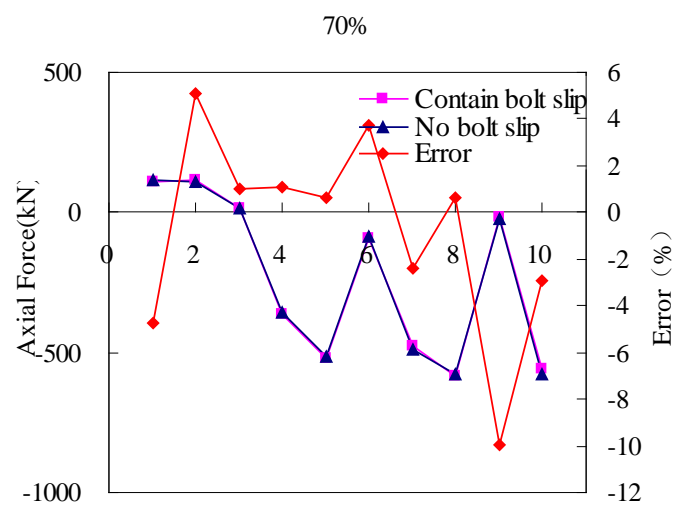

(b) $70 \%$ design load

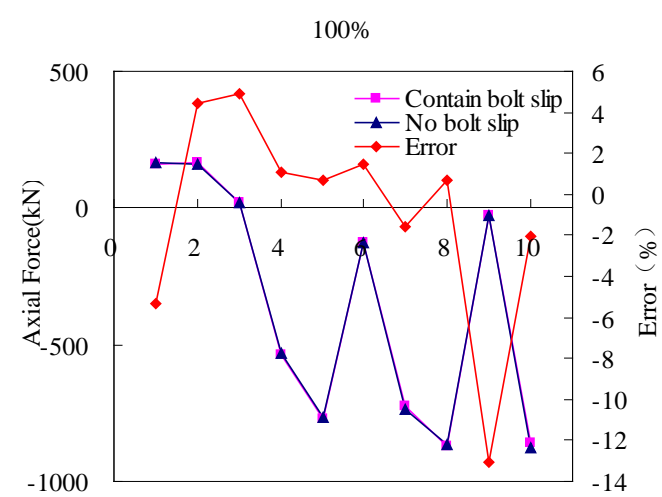

(d) $100 \%$ design load

Fig. 5 The analysis results of axial force

\subsection{Displacement of nodes}

Fig.6 shows the nodes displacement of the tower at different design load level. The location of the nodes can be found in the Fig.4 (b).As can be seen in the Figure, the node displacement is increased as the increasing of load level. However the error between the two numerical models was maintaining almost the same which is around $45 \%$. Therefore, the results shows that the joint slippage will greatly affect the deformation of the whole tower, especially at the top of the UHV tower, and it should pay more attention in the tower design. 


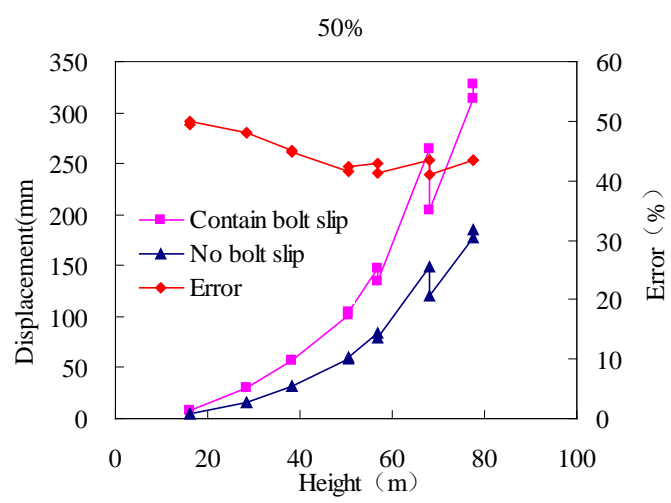

(a) $50 \%$ design load

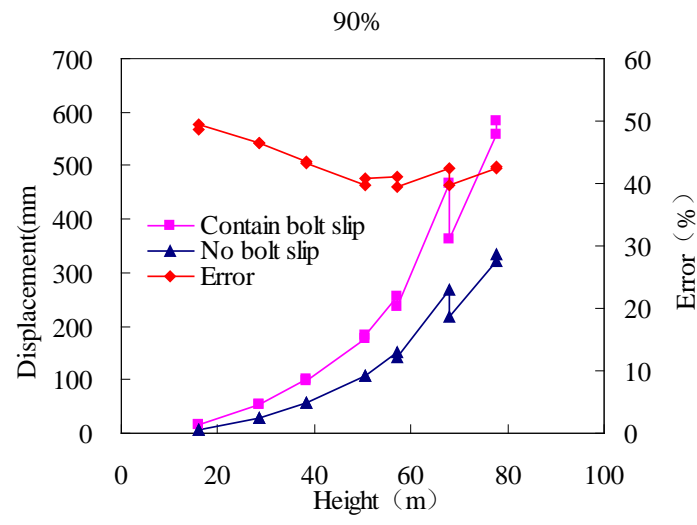

(b) $90 \%$ design load

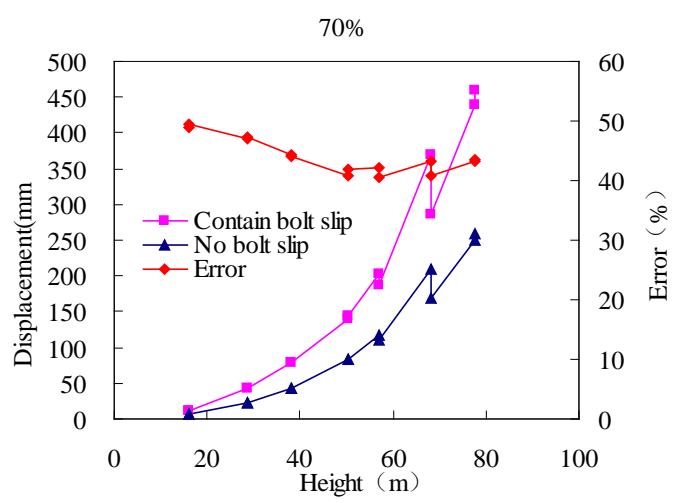

(b) $70 \%$ design load

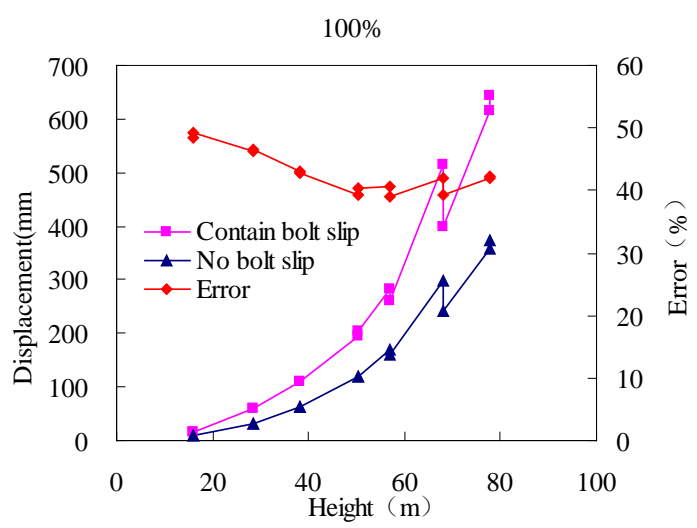

(b) $100 \%$ design load

Fig. 6 The analysis results of axial force

\section{Conclusions}

The bolted connecting is prone to slip results from external load in the transmission tower as the member is thin and the pre-tightening force of bolt is small, which will affect the inner force and the deformation of tower. Therefore, it should be more reasonable to consider the effects of slip bolt connection in UHV transmission tower design because of the large spatial dimension and design load. In this paper, a new design UHV transmission tower suffering from strong wind load was studied with nonlinear static analysis method, and the joint slippage effects are including during the analysis. After comparing the results of UHV tower model with considering joint slippage effects and without considering joint slippage effects. the following conclusion are: 1) joint slippage will slightly influence the inner force of the member, and which will increased with the load; 2) joint slippage will greatly increase the deformation of the tower, especially at the top, so it should pay more attention in the tower design.

\section{Acknowledgements}

The authors acknowledge the financial support provided by the science and technology projects of State Grid (Dynamic characteristics and ultimate behavior of lattice tower in the mining area) and the Natural Science Foundation of China (51408221).

\section{References}

[1]Ungkurapinan N., Chandrakeerthy S.R.De S., 2003, Rajapakse R.K.N.D., Yue S.B. Joint slip in steel electric transmission towers . Engineering Structures, 25:779-788.

[2]Jiang W. Q, Wang Z. Q., G. McClure,et al., 2011, Accurate modeling of joint effects in lattice transmission towers. Engineering Structures, 33(5):1817-1827. 
[3]Aibermani F. G. A., 1992, Kitipornchai S. Elastoplastic nonlinear analysis of flexibly jointed space frames. ASCE Journal of Structural Engineering, 118(1):108-127

[4]Chan S. L., Chui P. P. T., 2000, Non-linear static and cyclic analysis of semi-rigid steel frames. Elsevier Science

[5]Chan S. L., Cho S. H. 2008a, Second-order analysis and design of angle trusses Part I: Elastic analysis and design. Engineering Structures, 30(3):616-625.

[6]Chan S. L., Cho S. H., 2008b, Second-order analysis and design of angle trusses Part II: Plastic analysis and design. Engineering Structures, 30(3):626-631.

[7]Chen W. F., Chan S. L. 1995, Second-order inelastic analysis of steel frames using element with midspan and end springs. Journal of Structural Engineering, 121(3):530-41 